\title{
Evaluation of 5-aminolevulinic acids induced photodynamic inactivation on Streptococcus mutans and Streptococcus sobrinus; by using two light emitting diode wavelengths (In vitro study).
}

\author{
Hawzhen Masoud M Saeed ${ }^{1 *}$, Bestoon Mohammad Faraj ${ }^{1}$, Balssam Mohammad Mirdan ${ }^{2}$ \\ ${ }^{1}$ Conservative Department, College of Dentistry, University of Sulaimani, Sulaimani, Iraq \\ ${ }^{2}$ Oral Surgery Department, College of Dentistry, University of Kirkuk, Kirkuk, Iraq
}

\begin{abstract}
The aim of this study was to evaluate the effect of photoactive-dye (5- aminolevulinic acid) in inhibition of Streptococcus mutans and Streptococcus sobrinus by using different light emitting diode wavelengths (Red light $635 \mathrm{~nm}$ and Blue light $440 \mathrm{~nm}$ ). The minimum inhibitory concentration and minimum bactericidal concentration was determined by using 96-well plate in a dark room. The result of the study exhibited that both types of bacteria were inactivated but at different concentration, the $S$. mutans was inhibeted at $64.5 \mathrm{mM}$ whereas, the $S$. sobrinus show inhibition at $32.25 \mathrm{mM}$, both types of light were capable to activating the 5- aminolevulinic acid and lead to significant reduction in Mutans Streptococci and Sobrinus Streptococci. But the Mutans Streptococci need more concentration to be in activated this may be due to the type of bacterial gene.
\end{abstract}

Keywords: Antibacterial agents, Microbiology, Photodynamic Therapy, 5-aminolevulinic acids, Streptococcus mutans, Streptococcus sobrinus.

Accepted on July 26, 2019

\section{Introduction}

Photodynamic therapy, also known as PDT, combines the use of non-toxic photosensitizing dyes with a visible light of appropriate wavelength [1]. Photosensitive substances absorb energy from light and become activated, producing highly reactive oxygen species, which results in cell damage and cell death [2].

In dentistry, PDT has been investigated for the treatment of oral infections, such as caries, pulpitis, and periodontal disease, mucosal and endodontic infections [3]. Photodynamic therapy is of great interest in the field of dentistry, due to antibacterial effect, including the effectiveness against oral microorganisms related to dental caries [4]. In the past, dentistry was concerned about the load of bacteria that remained after cavity preparation, in order to avoid secondary caries development. The recommendation was to remove all carious dentin. However, subsequent research has shown that the influence of microorganisms on the development of secondary caries under these circumstances is not such an important determining factor [5]. Nevertheless, the infected dentin, which is infected and incapable of mineralization, should be removed to prevent pulp inflammation and potential pulp exposure in deep cavities. In addition to this, the presence of infected dentine decreases the adhesion properties of the restorative materials, reducing the retention of sealing material $[6,7]$. Therefore, the use of PDT reduces the number of microorganisms and subsequently reduces the chance of pulp inflammation, as well as reduces the potential loss of restorative sealant [7].

According to the Global Burden of Disease 2010 study, untreated dental caries in permanent teeth is the most prevalent disease across the globe, affecting 2.4 billion people, while untreated dental caries in deciduous teeth was found to be the tenth-most prevalent condition, affecting 621 million children worldwide [8]. Dental caries is defined as the "localized destruction of susceptible dental hard tissues by acidic byproducts from bacterial fermentation of dietary carbohydrates" [9]. Hence, dental caries is considered as a highly dynamic process on the tooth surface with the cariogenic biofilm representing the vital driving force [10]. According to that among Mutans streptococci (MS), Streptococcus mutans and Streptococcus sobrinus were the most isolated microorganisms from the majority of human dental caries [11]. It is well known that dental caries is a multifactorial disease and the heterogeneity among the members of MS is one of the prime factors in the initiation of the disease, the detection of $S$. sobrinus species in high caries incidence subjects was often correlated with high caries activity, though higher prevalence rates of $S$. mutans was reported [12].

In the researches, a photoactive dye, called a photosensitizer, is taken up into cells and is irradiated with light of an appropriate wavelength. This may result in cell death through the production of active oxygen species [13]. 
It has been known since the beginning of the last century that micro-organisms can be killed by the combination of dyes and light, but the interest in antimicrobial PDT was hampered by the introduction of antibiotics. In recent years, the emergence of antibiotic-resistant strains, such as methicillin-resistant Staphylococcus aureus and vancomycin-resistant Enterococcus faecalis, stimulated a search for alternative treatments. PACT has the potential to be such an alternative, especially for the treatment of localized infections of the skin and the oral cavity. Micro-organisms that are killed by PACT include bacteria, fungi, viruses, and protozoa. The development of resistance to PACT appears to be unlikely, since, in microbial cells, singlet oxygen and free radicals interact with several cell structures and different metabolic pathways. PACT is equally effective against antibiotic-resistant and antibiotic-susceptible bacteria, and repeated photosensitization has not induced the selection of resistant strains [14]. It has been known since the beginning of the last century that micro-organisms can be killed by the combination of dyes and light, but the interest in antimicrobial PDT was hampered by the introduction of antibiotics. In recent years, the emergence of antibiotic-resistant strains, such as methicillin-resistant Staphylococcus aureus and vancomycinresistant Enterococcus faecalis, stimulated a search for alternative treatments. PACT has the potential to be such an alternative, especially for the treatment of localized infections of the skin and the oral cavity. Micro-organisms that are killed by PACT include bacteria, fungi, viruses, and protozoa. The development of resistance to PACT appears to be unlikely, since, in microbial cells, singlet oxygen and free radicals interact with several cell structures and different metabolic pathways. PACT is equally effective against antibiotic-resistant and antibiotic-susceptible bacteria, and repeated photosensitization has not induced the selection of resistant strains [14].

5-Aminolevulinic acid (ALA) itself is not a photosensitizer but serves as the biological precursor of the photosensitizer, protoporphyrin IX (PpIX), in the heme biosynthesis pathway. When 5-ALA is topically applied on the oral lesions or systemically administrated by the patients, the lesion epithelial cells and results in accumulation of relatively high concentration of PpIX in these cells will absorb it [15].

The aim of this study was to assess the effect of 5Aminolevulinic acids in inhibition of $S$. mutans and $S$. sobrinus and determine the minimum concentration that can inhibit the bacterial growths.

\section{Materials and Methods}

\section{Isolation and identification of the mutans streptococci species}

The process of isolation and identification of the Mutans streptococci species (Streptococcus mutans and Streptococcus sobrinus) were performed according to a protocol developed and reported by Villhauer et al. [16]. Briefly, the protocol includes preliminary identification based on colony morphology on selective agar media (SB-20M) followed by polymerase chain reaction (PCR) confirmation for species identification using primers targeting specific regions of the glucosyltransferase (gtf) genes of Streptococcus mutans (SM) and Streptococcus sobrinus (SS). This method of isolation and identification was found to be highly accurate, more rapid than the previous methodologies used and easily learned, and resulted in more efficient use of both time and material resources. The SB-20M agar medium was selected for identification of the Mutans streptococci species because of the distinctive colony morphologies seen that allow for distinguishing between SM and SS colonies [17].

Whole mouth plaque samples were collected from volunteer patients at the Pedodontics clinic (College of Dentistry/ University of Sulaimani) by swabbing all smooth surfaces of the dentition with sterile cotton swabs on a wooden steak [16]. The head of the cotton swabs were cut into sterile $10 \mathrm{ml}$ plastic tubes containing sterile $5 \mathrm{ml}$ Phosphate-buffered saline (PBS) solution $(\mathrm{pH}=7.4)$. The plaque samples were vortexed for 30 seconds to disperse the plaque microorganisms and release the bacteria into the PBS solution and aliquots of $25 \mu \mathrm{l}$ volumes from the plaque samples were transferred to the SB-20M medium and incubated for 72 Hours in an anaerobic condition using anaerobic jar and anaerobic gas generator. Suspected colonies of mutans streptococci were sub-cultured on the same media and in the same anaerobic condition to get pure isolates of the microorganisms.

SM and SS isolates were streaked from the SB-20M agar to Tryptic Soy agar (TSA; Oxoid, UK) and incubated anaerobically. When sufficient growth was obtained, a rapid DNA extraction method was used to obtain DNA from all MS isolates. A colony PCR procedure was performed for bacterial DNA identification at MegaGene Lab (Harem Private Hospital, Sulaymaniyah, Iraq). Bacterial DNA were released by boiling a bacterial colony in $50 \mu \mathrm{l}$ distilled deionized water $\left(\mathrm{dd} \mathrm{H}_{2} \mathrm{O}\right.$ : GeNet Bio, Korea) for 3 minutes at $95^{\circ} \mathrm{C}$. Five microliters $(5$ $\mu \mathrm{l})$ from this suspension was mixed with $2 \mu \mathrm{l}$ forward primer $(\sim 5-10 \mathrm{pmol} / \mu \mathrm{l}), 2 \mu \mathrm{l}$ reverse prime $(\sim 5-10 \mathrm{pmol} / \mu \mathrm{l})$, and $10 \mu \mathrm{l}$ of Prime Taq Primix (GeNet Bio, Korea) for performing the PCR procedure. Prime Taq 2X Primix (GeNet Bio, Korea) composed of: Prime Taq DNA Polymerase 1 unit/10 $\mu 1,2 \mathrm{X}$ reaction buffer, $4 \mathrm{mM} \mathrm{MgCl}_{2}$, enzyme stabilizer, sediment, loading dye, $\mathrm{pH} 9.0$ and $0.5 \mathrm{mM}$ each of dATP, dCTP, dGTP, dTTP. DNA amplification was performed in a PCR thermal cycler under the following conditions: initially $5 \mathrm{~min}$ at $95^{\circ} \mathrm{C}$, followed by 30 cycles of denaturation at $95^{\circ} \mathrm{C}$ for 30 seconds, annealing at $55^{\circ} \mathrm{C}$ for 30 seconds, and elongation at $72^{\circ} \mathrm{C}$ for 1 min, ending with $5 \mathrm{~min}$ at $72^{\circ} \mathrm{C}$ (Oho et al., 2000). Amplified PCR products were electrophoresed on a $1.5 \%$ agarose gel and stained with ethidium bromide. Gel images were captured using a UV transilluminator and digital camera.

Based on the results reported by Villhauer et al. [16] on several primers sets from different studies, the following primers reported by Oho etal (2000) performed better with minimal false positive or false negative results when used to compare for identification of clinical and type strains of Mutans streptococci. Streptococcus mutans (gtfB-F:5 ' - 
Evaluation of 5-aminolevulinic acids induced photodynamic inactivation on Streptococcus mutans and Streptococcus sobrinus; by using two light emitting diode wavelengths (In vitro study).

ACTACACTTTCGGGTGGCTTGG-3 ' and gtfB-R:5 ' CAGTATAAGCGCCAGTTTCATC-3') with 517 bp amplicon size and $55^{\circ} \mathrm{C}$ annealing temperature

and for Streptococcus sobrinus (gtfI-IN-F:5 ' TGGTATCGTCCAAAATCAATCC-3 ' and gtfI-IN-R:5 ' AGATTTGCAGTTGGTCAGCATC-3') with 664 bp amplicon size and $55^{\circ} \mathrm{C}$ annealing temperature (Oho et al., 2000). Since these two species are closely related microorganism, we opted to cross check every sample for both microorganisms to rule out the possibility of mixed colonies.

\section{Preparation of $A L A$ solution}

A stock solution of 10 Molar (M) ALA was prepared by dissolving ALA in $0.1 \mathrm{M}$ PBS (pH 7.4) prior to the experiment. The ALA stock and diluted solutions were used within 2 hours after the preparation to ensure its stability.

\section{Bacterial strains and growth conditions}

This study was conducted with Strreptococcus mutans and Streptococcus sobrinus (clinically isolated strains) as seen in Figure 1. The strains were grown in Brain heart infusion broth separately for 24 hours at $37^{\circ} \mathrm{C}$ in atmosphere $10 \% \mathrm{CO}_{2}$ controlled by a low-temperature incubator (LE-509; YIH DER Instruments, Taipei, Taiwan).

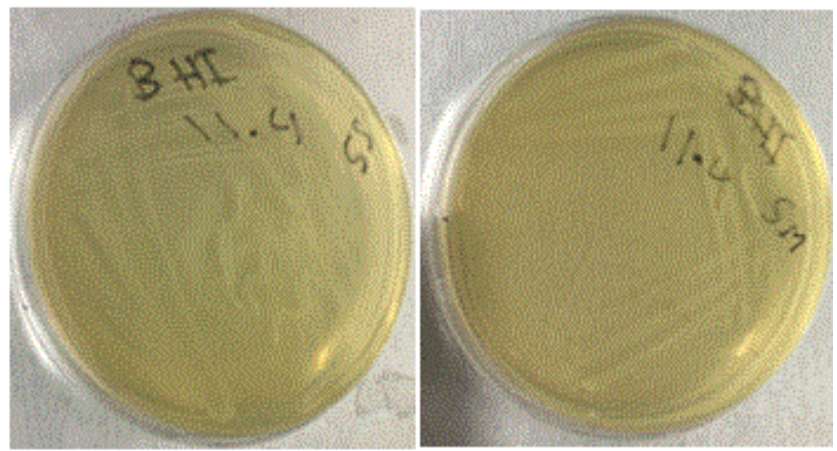

Figure 1. Brain heart infusion agar inoculated with S. sobrinus and S. mutans.

The broth cultures were then spread on BHI agar medium and then incubated at $37^{\circ} \mathrm{C}$ for 24 hours. This incubation process was repeated for three times to produce the bacterial strains containing approximately $10^{8}$ colony-forming units (CFU)/ $\mathrm{mL}$.

\section{Photodynamic inactivation (PDI) of bacterial cells}

For PDI, bacterial cells in the broth cultures were centrifuged, washed three times with PBS, and then suspended in PBS to obtain a cell suspension about $108 \mathrm{CFU} / \mathrm{mL}$. Aliquots of suspensions $(0.4 \mathrm{~mL})$ of ALA $(10 \mathrm{M})$ added to $3.6 \mathrm{~mL}$ of BHI broth and 1:100 bacteria was added for each type of bacteria separately, double fold dilution method were done in nine prepared BHI broth each of the 9 remaining tubes contain 2 $\mathrm{mL}$ after adding $2 \mathrm{~mL}$ from first tube (that contain $0.4 \mathrm{ml}$ of ALA and $3.6 \mathrm{ml}$ of BHI and bacteria) till the last tube and discarding $2 \mathrm{~mL}$ from the last one, and then $0.2 \mathrm{~mL}$ of each tube then transferred into 96-well plates three wells were used for each diluted stock is shown in Figure 2.

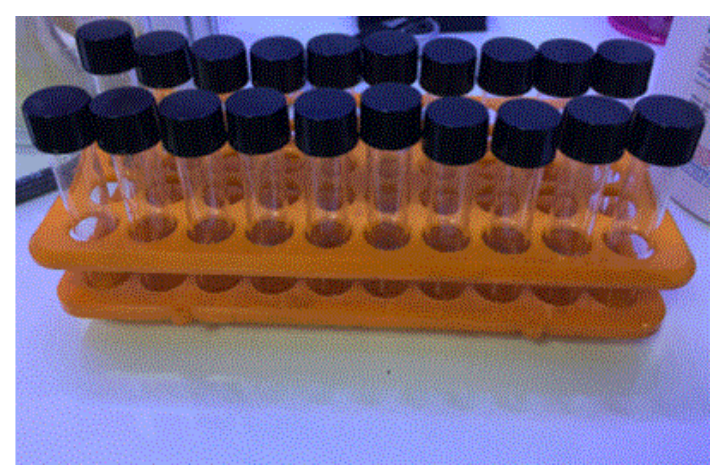

Figure 2. Double fold dilution for both S. mutans and S. sobrinus.

Samples were incubated for 60 minutes in the dark and then irradiated at room temperature $\left(25^{\circ} \mathrm{C}\right)$.

Since two 96-well plates were used and for each types of bacteria S. mutans and S. sobrinus, Three wells are used with the same concentration (triplicate), the first 96-well plate were irradiated with red light LED, the second 96-well plate were irradiated with blue light each for 30 seconds is shown in Figure 3.

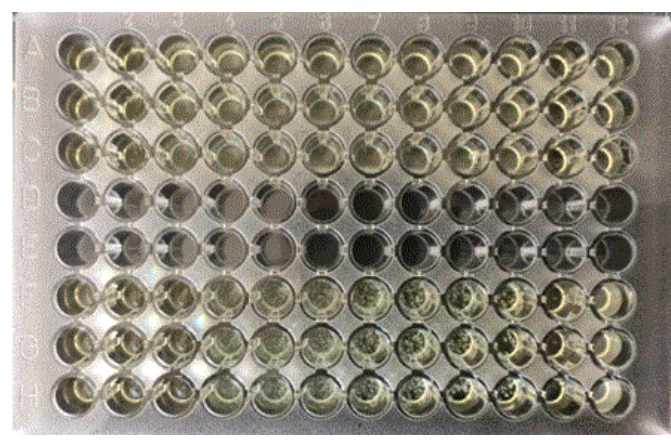

Figure 3. 96-well plate (A, B, C) raw contain replica of $S$. mutans, $(F$, $G, H)$ raw contain replica of $S$. sobrinus.

The light source used for ALA irradiation consisted of a lightemitting diode (LED) array with the wavelength centered at $635 \mathrm{~nm}$ for 30 seconds, with an irradiance set as required light doses. The irradiated bacterial cells were incubated for an additional 18 hours at $37^{\circ} \mathrm{C}$.

The second 96 well plates were irradiated with LED with 440 $\mathrm{nm}$ wavelengths for 30 seconds also; the irradiated bacteria were incubated also for 18 hours at $37^{\circ} \mathrm{C}$.

After incubations for 18 hours a lop full was taken from the well that showed complete inhibition and compare it with one well before and wells after it, and put on BHI agar plate (three plates were used for each well) to shows bacterial survival rate and to check the that the ALA at which concentration can completely inhibit the bacteria and after that we put it in incubator for 24 hours. 


\section{Results}

Since all the plates (96-wells) were evaluated by using Microplate Autoreader and by naked eyes of two observers to determine the effect of different concentration of ALA on both types of bacteria and to determine the effect of different light (blue and red lights). Both plates' shows bacterial inhibition at certain concentration of the photoactive dye, after observations by naked eyes, as some wells show non-bacterial growth or there were no any turbidity when examined by two observers' when comparing with the wells before or after, From each these wells a lop full where taken and triplicated on BHI agar and incubated at $37^{\circ} \mathrm{C}$ for 18 hours, after that the growths of both types can be analysed by colony growths in the incubated plates.
Streptocoocus mutans can be inhibited at a concentration 62.5 millimolar (mM) of ALA, whereas Streptococcus sobrinus can be inhibited at $31.25 \mathrm{mM}$. For Streptococcus mutans $31.25 \mathrm{mM}$ showed little bacterial growth or very little colonies and 125 $\mathrm{mM}$ showed complete bacterial inhibition. However, $S$. sobrinus showed little bacterial growth or colony at $15.6 \mathrm{mM}$ and no growth at $62.5 \mathrm{mM}$ as predicted in the Tables 1 and 2 .

Table 1. Concentration of 5-ALA that can inhibit the bacterial growth.

\begin{tabular}{llll}
\hline Type of bacteria & $\begin{array}{l}\text { Little bacterial } \\
\text { growth }\end{array}$ & $\begin{array}{l}\text { No bacterial } \\
\text { growth }\end{array}$ & $\begin{array}{l}\text { No bacterial } \\
\text { growth }\end{array}$ \\
\hline Streptococcus mutans & $31.25 \mathrm{mM}$ & $62.5 \mathrm{mM}$ & $125 \mathrm{mM}$ \\
\hline Streptococcus sobrinus & $15.6 \mathrm{mM}$ & $31.25 \mathrm{mM}$ & $62.5 \mathrm{mM}$ \\
\hline
\end{tabular}

Table 2. Concentration of 5-ALA that shows show little bacterial and non-bacterial growth in activation light.

\begin{tabular}{lllc}
\hline \multicolumn{1}{c}{ Type of bacteria } & Activation light & $\begin{array}{c}\text { Concentration of 5-ALA shows } \\
\text { little bacterial growth }\end{array}$ & $\begin{array}{c}\text { Concentration of 5-ALA shows } \\
\text { Non- bacterial growth }\end{array}$ \\
\hline Streptococcus mutans & Red (LED) light $635 \mathrm{~nm}$ & $31.25 \mathrm{mM}$ & $\begin{array}{c}\text { Concentration of 5-ALA } \\
\text { shows bacterial growth }\end{array}$ \\
\hline Streptococcus mutans & Blue (LED) light $440 \mathrm{~nm}$ & $31.25 \mathrm{mM}$ & $62.5 \mathrm{mM}$ \\
\hline Streptococcus sobrinus & Red (LED) light $635 \mathrm{~nm}$ & $15.6 \mathrm{mM}$ & $31.25 \mathrm{mM}$ \\
\hline Streptococcus sobrinus & Blue (LED) light $440 \mathrm{~nm}$ & $15.6 \mathrm{mM}$ & $31.25 \mathrm{mM}$ \\
\hline
\end{tabular}

All plates (Red light and blue light irradiated plates) showed that both types of bacteria could be inhibited at the same concentration even if different light wavelengths were used for activation of the photoactive dye in different plates as seen in Figures 4-8.

\section{Discussion}

This study evaluated particularly the minimum concentration of 5-ALA that can inhibit the growth both strains of clinically isolated S.mutans and S.sobrinus.

Significant decrease on the viability of microorganisms was observed when both strains exposed to different light source (blue light $440 \mathrm{~nm}$ and red light $635 \mathrm{~nm}$ ), both types of bacteria showed significant inhibition, when ALA was applied with two light source, because of reactive oxygen species (ROS), such as singlet oxygen and free radicals, which are cytotoxic to bacterial cells [18]. ROS can cause bacterial lethal injury by means of damage to assorted range of target, mainly bacterial DNA, and the cytoplasmic membrane [19].

However, there was significant difference between the concentrations of ALA that can inhibit both types of bacteria.

S. mutans can be killed at the concentration higher than that of S. sobrinus, and this may be related to the type of bacteria. Furthermore, this investigation found a significant reduction in the viable numbers of $S$. mutans and $S$. sobrinus after photosensitization, which is significant, as these species are amongst those reported to be most highly associated with caries in humans [20].

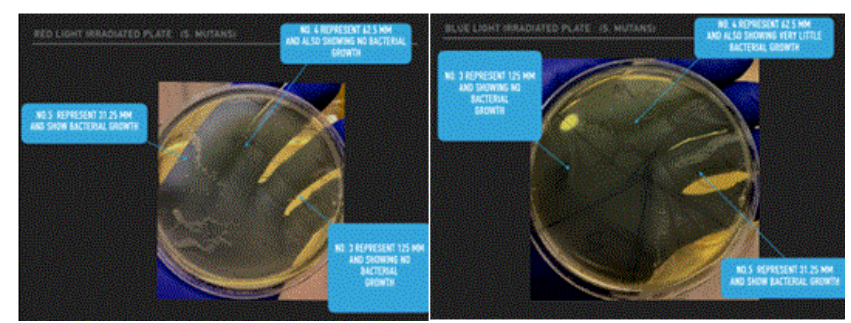

Figure 4. A lop full of 96 well after incubation for 24 hours in incubator shows bacteria colonies for concentration that could not completely inhibit the bacterial growth and no colonies for whose that completely inhibit it is growth.

Dental caries may be a disease well suited to photosensitization therapy. Caries is often a localized infection, and so the sensitizer could be applied to the lesion by means of a syringe and the light could then be delivered via an optical-fibre [21].

If bacteria within carious lesions could be eradicated by photosensitization in vivo, there would be beneficial consequences for dental health. Infected or damaged dentine could be better preserved, thereby making patient treatment easier (for both dentist and patient) by enabling lesions to be restored with minimal tissue removal, and improving the longterm prognosis for the repaired tooth [22-25].

In addition, the option of a LED light instead of a laser light has obvious financial advantages when compared with photosensitization using conventional lasers. Furthermore, the large band emission of an LED (440 nm-635 nm) may be interesting, as there is light emission in the entire absorption 
Evaluation of 5-aminolevulinic acids induced photodynamic inactivation on Streptococcus mutans and Streptococcus sobrinus; by using two light emitting diode wavelengths (In vitro study).

spectrum of ALA (635 nm), which may promote optimization of the photodynamic process.

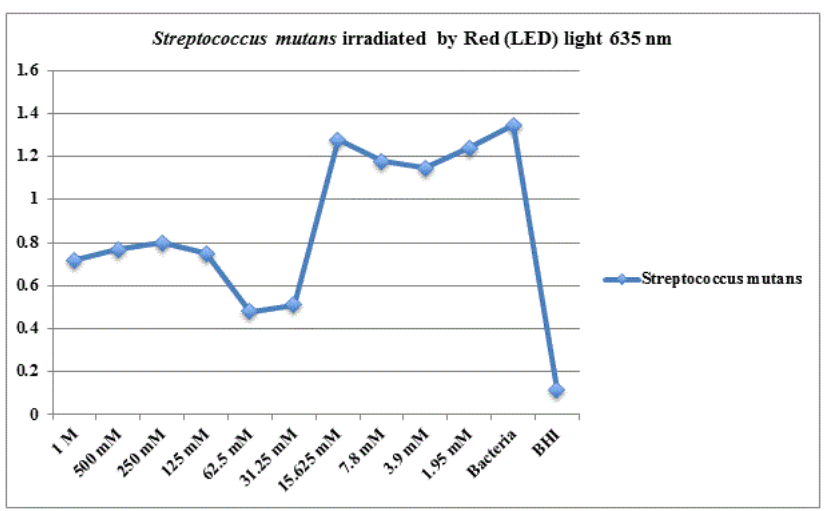

Figure 5. Streptococcus mutans irradiated by Red (LED) light 635 nm.

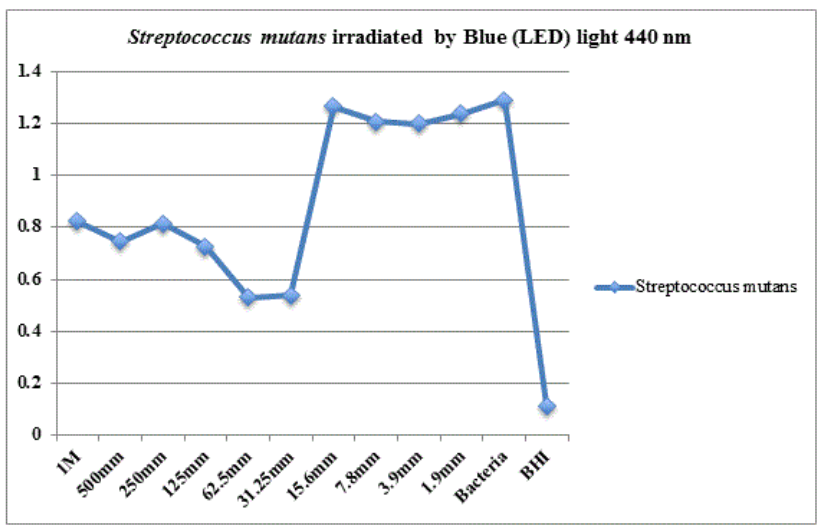

Figure 6. Streptococcus mutants irradiated by Blue (LED) light 440 nm.

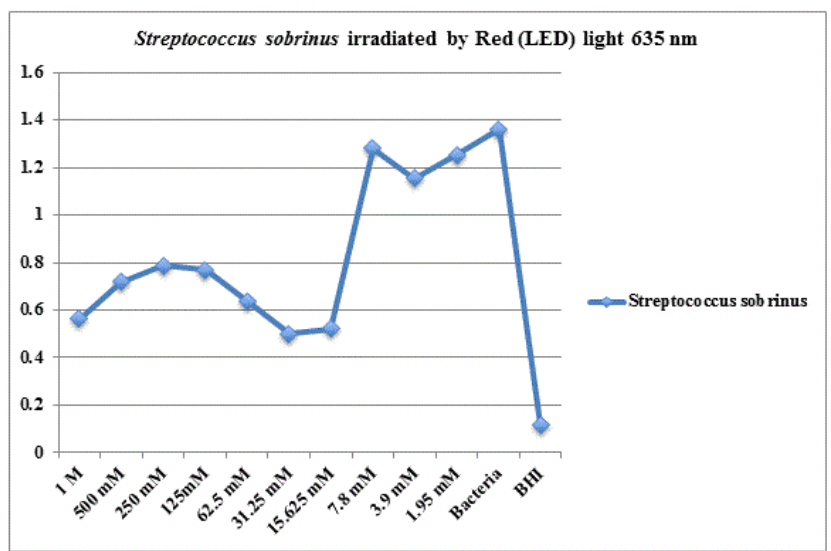

Figure 7. Streptococcus sobrinus irradiated by Red (LED) light 635 $n m$.

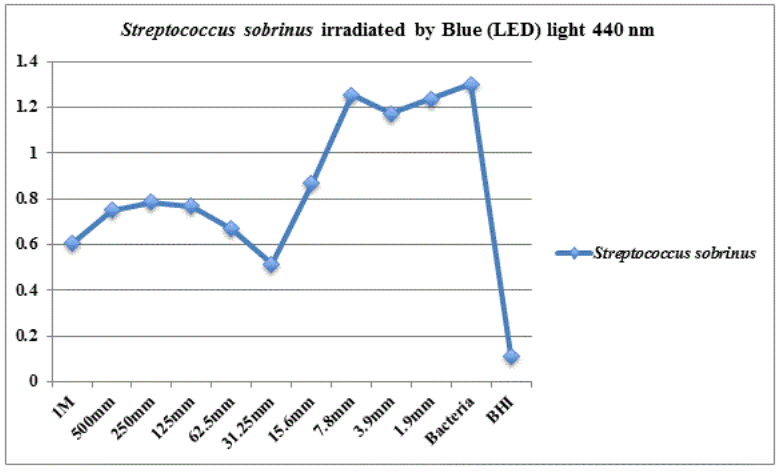

Figure 8. Streptococcus sobrinus irradiated by Blue (LED) light 440 $n m$.

\section{Conclusion}

In conclusion using ALA can inactivate both types of bacteria, but at different concentrations. In addition, further study needed to evaluate it is effect on other type of bacteria that induces dental caries since different type of bacteria involved in development of carious lesion. Also in vivo study should be carried out to determine it is effect inside the oral cavity.

\section{Acknowledgement}

We would like to thank the College of biology, University of Sulaimani for their support and guidance, many thanks to Dr. Aras Jalal Noori and Dr. Hastyar Najmuldeen for their guidance.

\section{References}

1. Baptista F, Santos DA, Silva AM, Mota J, Santos R, Vale S, Ferreira JP, Raimundo AM, Moreira H, Sardinha LB. Prevalence of the Portuguese population attaining sufficient physical activity. Med Sci Sports Exerc 2012; 44: 466-473.

2. Wilson BC, Patterson MS. The physics, biophysics and technology of photodynamic therapy. Phys Med Biol 2008; 53: 61-109.

3. Yildirim AE, Divanlioglu D, Nacar OA, Dursun E, Sahinoglu M, Unal T, Belen AD. Incidence, hormonal distribution and postoperative follow up of atypical pituitary adenomas. Turk Neurosurg 2013; 23: 226-231.

4. Stringer C. Modern human origins: progress and prospects. Philos Trans R Soc Lond B Biol Sci 2002; 357: 563-579.

5. Kidd EAM. Clinical threshold for carious tooth removal. Dent Clin North Am. 2010; 54: 541-549.

6. Hayashi M, Fujitani M, Yamaki C, Momoi Y. Ways of enhancing pulp preservation by stepwise excavation: A systematic review. J Dent 2011; 3 : 95-107.

7. Hahn CL, Liewehr FR. Relationships between caries bacteria, host responses, and clinical signs and symptoms of pulpitis. J Endod. 2007; 33: 213-219.

8. N.J. Kassebaum, E. Bernabé, M. Dahiya, B. Bhandari, C.J.L. Murray, W. Marcenes, Global burden of untreated 
caries: A systematic review and metare-gression. J Dent Res 2015; 94: 650-658.

9. R.H. Selwitz, A.I. Ismail, N.B. Pitts. Dental Caries Lancet 369. 2007; 3: 51-59.

10. E.A.M. Kidd, How clean must a cavity be before restoration. Caries Res 2004; 38: 305-313.

11. Colak H, Dülgergil CT, Dalli M, Hamidi MM. Early childhood caries update: A review of causes, diagnoses, and treatments. J Nat Sci Biol Med 2013; 4: 2938.

12. Saravia ME, Nelson-Filho P, Ito IY, da Silva LA, da Silva RA, Emilson CG. Morphological differentiation between S. mutans and S. sobrinus on modified SB-20 culture medium. Microbiological Research. 2011;166: 63-67.

13. Malik Z, Hanania J, Nitzan Y. Bactericidal effects of photoactivated porphyrins: An alternative approach to antimicrobial drugs. J Photochem Photobiol B 1990; 5: 281-293.

14. Wainwright M, Crossley KB. Photosensitising agentsCircumventing resistance and breaking down biofilms: A review. International Biodeterioration \& Biodegradation 2004; 53: 119-126.

15. Chang AH, Parsonnet J. Role of bacteria in oncogenesis. Clin Microbiol Rev 2010; 23: 837-857.

16. Villhauer AL, Lynch DJ, Drake DR. Improved method for rapid and accurate isolation and identification of Streptococcus mutans and Streptococcus sobrinus from human plaque samples. Journal of Microbiological Methods. 2017; 139: 205-209.

17. Saravia ME, Nelson-Filho P, Ito IY, da Silva LA, da Silva RA, Emilson CG. Morphological differentiation between S. mutans and S. sobrinus on modified SB-20 culture medium. Microbiological Research. 2011;166: 63-67.

18. Fu XJ, Fang Y, Yao M. Antimicrobial photodynamic therapy for methicillin-resistance Staphylococcus aureus infection. Biomed Res Int. 2013;13: 157-159.

19. Vatansever F, de Melo WC, Avci P, Vecchio D, Sadasivam M, Gupta A, Chandran R, Karimi M, Parizotto NA, Yin R,
Tegos GP, Hamblin MR. Antimicrobial strategies centered around reactive oxygen species--bactericidal antibiotics, photodynamic therapy, and beyond. FEMS Microbiol Rev 2013;37: 955-989.

20. Banas JA, Vickerman MM. Glucan-binding proteins of the oral streptococci. Crit Rev Oral Biol Med 2003; 14: 89-99.

21. Wilson M. Photolysis of oral bacteria and its potential use in the treatment of caries and periodontal disease. J Appl Bacteriol. 1993; 75: 299-306.

22. Wilson M. Lethal photosensitization of oral bacteria and its potential application in the photodynamic therapy of oral infections. Photochem Photobiol. 2004; 39: 412-418.

23. Chien-Ming Hsieh, Yen-Hao Huang, Chueh-Pin Chen, BoChuan Hsieh, Tsuimin Tsai. 5 Aminolevulinic acid induced photodynamic inactivation on Staphylococcus aureus and Pseudomonas aeruginosa. J Food Drug 2014; 22: 350-35.

24. Oho T, Yamashita Y, Shimazaki Y, Kushiyama M, Koga T. Simple and rapid detection of Streptococcus mutans and Streptococcus sobrinus in human saliva by polymerase chain reaction. Oral Microbiology and Immunology 2000; 15: 258-262.

25. Toi CS, CleatonJones PE, Daya NP. Mutans streptococci and other cariesassociated acidogenic bacteria in five yearold children in South Africa. Oral Microbiol Immunolo 1999; 1: 238-243.

\section{*Correspondence to}

Hawzhen Masoud M Saeed

Conservative department,

College of dentistry

University of Sulaimani, Iraq 